\title{
Optimization of abiotic conditions suitable for the production of biodiesel from Chlorella vulgaris
}

\author{
Sanniyasi Elumalai*, Velu Prakasam and Ramganesh Selvarajan \\ Department of Plant Biotechnology, Presidency College, Chennai-600005, India \\ ananandal@gmail.com*
}

\begin{abstract}
The present study reports the production of fatty acids by microalgae under the influence of light and dark condition. Microalgae are renewable resource containing rich lipids in their body and has the potential to refill the partial energy demands in an eco-friendly way. We isolated an indigenous green alga (Chlorella vulgaris) as a potent source for biodiesel. To get better yield of biofuel, the growth of the microalgal isolate was optimized with the addition of nutrients and salts under light and dark conditions. The lipid fractions were extracted from the biomass through solvent extractions and the fractions were analyzed for biodiesel under GC-MS. The percentage of lipids synthesized from $C$. vulgaris under light and dark conditions were analyzed and compared. The algae from dark sample shows rich in saturated fatty acid (capric acid, lauric acid \& myristic acid) and considerable amount of PUFA (hexadecatrienoic acid, stearidonic acid, eicosapenaenoic acid, docosahexaenoic acid) when compare to algae grown under light. So the algae grown in dark condition is an excellent source for high yield of saturated fatty acids.
\end{abstract}

Keywords: Biofuel, biodiesel, Chlorella vulgaris, gasoline, renewable energy.

Abbreviations: FTIR: Fourier Transform Infra-Red spectroscopy, GC-MS: Gas chromatography-Mass spectroscopy, FA-Fatty acids, MUFA-Mono unsaturated fatty acid, PUFA: Poly unsaturated fatty acid.

Introduction

Recent spur in biofuel research is to reduce our dependence and depletion of petro oil and controlling gaseous pollution around the world. Besides, the biofuel production from photosynthetic algae is considered as a process to produce renewable energy for global warming mitigation. Under certain growth conditions, many micro algae can produce lipids that are suitable for conversion to biodiesel.

Biodiesel is the monoalkyl esters of long chain fatty acids, an alternative for fossil fuel. The most common biodiesel constituent used today is fatty acid methyl esters. Biodiesel is non-toxic completely biodegradable with reduced sulfur and carbon monoxide emission. It would be cut down by $30 \%$ and $10 \%$ respectively. The world total biodiesel production was estimated to be around 1.8 billion liters in 2003 (Fulton, 2004). Although there was no increase in biodiesel production between 1996 and 1998, a sharp increase in biodiesel production was observed in the past 5 years. It is speculated that the production of biodiesel will be further tremendously increased because of increasing demand for fuels and "cleaner" energy globally (Huang et al., 2010). The ability of algae to fix $\mathrm{CO}_{2}$ can also be an interesting method of removing gases from power plants and thus can be used to reduce greenhouse gases with a higher production of micro algal biomass and consequently higher biodiesel yield (Milne et al., 1990; Miao \& Wu, 2006). Microalgae is an autotrophs, growing in water, have fewer and more predictable process variables (sunlight, temperature) than higher plant systems, allowing easier extrapolation from one site, even climatic condition, to others. Thus, fewer site specific studies are required for microalgae than, for example, tree farming. Also, microalgae grow much faster than higher plants and require much less land areas ( Widjaja, 2009). Algae has the potential to deliver five to ten times more oil per hectare than conventional cropland biofuels ('Algae biofuel could launch new coastal industry', Maritime Journal, 14 April 2010).

Oil content in micro algae can exceed $80 \%$ by weight of dry biomass (Khan et al., 2009). Apart from this, it is a photosynthetic organism can grow in minimal nutrient supplements (water \& photon, $\mathrm{CO}_{2}$ ); easy mass cultivation, extraction and purification procedures make them suitable for huge biodiesel production ( $\mathrm{Hu}$ et al., 2008). The present study aims the production of fatty acids by microalgae under the influence of light and dark condition. Microalgal samples were collected from an ancient temple tank, Mylopore, Tamil Nadu, India. The algal microspore accumulates larger volume of lipid droplets due to light stress that is a good source for biodiesel production. The algae present in sample were identified and the amount of biodiesel produced in light and dark conditions were analyzed and compared by IR, GC-MS. In future, molecular level research will be carried out for revealing high algal oil production from these microalgae.

Materials and methods

Study site: The experiment was carried out in the research lab of department of plant biology and biotechnology, Presidency college (Autonomous), Chennai, India and Sopisticated analytical instrumentation facility (SAIF), IIT, Chennai, India.

Sample collection: Two samples were collected from a eutrophicated pond during day and night time at Tiruveteeshwarar temple, Triplicane, Chennai, India. Both the samples were enriched with addition of urea and 
maintained separately at light and dark condition throughout the process.

Light microscopy: The aliquots of sample was placed in centre of clean glass slide and covered by thin cover slips. The culture is observed under the light microscope by using high dry power lens $(45 \mathrm{x})$ and photographic results were recorded.

Culture identification: The collected microalgae sample was identified by the manual (Rosen, 1990).

Nile red staining: Nile red (9-(Diethylamino) $-5 \mathrm{H}$ benzo $[\alpha]$ phenoxazin- 5-one) staining is specifically used to identify and confirm the intracellular lipid droplets from the biological samples (Greenspan et al., 1985). To isolate the microalgal cells $(0.5 \mathrm{ml})$ from the collected water samples were achieved through centrifuge at $1,500 \mathrm{rpm}$ (Rev./min.) for $10 \mathrm{~min}$ and sediments were washed with physiological saline solution $(0.5 \mathrm{ml})$ for several times. The collected microalgal cells were suspended in $0.5 \mathrm{ml}$ of Nile red solution $(0.1 \mathrm{mg}$ of Nile $\mathrm{red} / \mathrm{ml}$ of acetone) and incubate for $10 \mathrm{~min}$ at room temperature. After washing with once, stained microalgal cells and the intracellular lipid contents observed by using fluorescent microscopy. (Matsunaga et al., 2009)

Oil extraction: The collected samples were filtered through sterilized fine cloth $\left(121^{\circ} \mathrm{C}\right.$ for $15 \mathrm{~min}$. at $15 \mathrm{lbs}$ ), the biomass were collected, separated and weighted. Biomass was macerated in mortar and pestle. The crushed algal cells were spread over a clean glass plate for air drying. The dried biomass were further broken into powder and mixed with citric acid for making algal beads, allow it for oven drying at $120^{\circ} \mathrm{C}$ for $1 \mathrm{~min}$. for evaporation of citric acid and water completely. Lipid presenting in algal cell contents were analyzed using petroleum ether, catalyst such as $\mathrm{NaOH}$ and methanol. The dried algae beads were soaked with petroleum ether (1:1 by vol) solvent in a beaker overnight. The amber colored oil extracts were collected on top of the solution and mixed with catalyst $(0.30 \mathrm{~g} \mathrm{NaOH}$ and 2 $\mathrm{ml}$ of methanol) for transesterification process. After that the solution was kept for $16 \mathrm{~h}$ to settle the biodiesel and sediment layers clearly (Sharif Hossain \& Salleh, 2008).
The results were compared with the petro based diesel and gasoline oils. The methyl esters of fatty acids were quantified by a gas chromatograph (Agilant-JEOL GC \& MS). The column (HP5) was fused silica $50 \mathrm{~m} \times 0.25 \mathrm{~mm}$ I.D. Analysis conditions were $20 \mathrm{~min}$. at $100^{\circ} \mathrm{C}, 3 \mathrm{~min}$ at $235^{\circ} \mathrm{C}$ for column temperature, $240^{\circ} \mathrm{C}$ for injector temperature, helium was the carrier gas and split ratio was 5:4. The weight percentages of fatty acids were approximated by the area of the detector response. The fatty acid methyl esters were identified by gas chromatography coupled with mass spectrometry.

FTIR spectrometry: The samples containing lipid fractions were analyzed in thalium bromide cell (Resolution: $4 \mathrm{~cm}^{-1}$, scan number: 3 , scan range: $450 \mathrm{~cm}^{1}$ to $4000 \mathrm{~cm}^{1}$ ) by FTIR (Perkin Elmer model spectrum-I PC). The spectra were recorded.

Results and discussion

Fig. 1. Lightmicroscopic observation of algae samples ( $a \& b)$ Chlorella vulgaris.

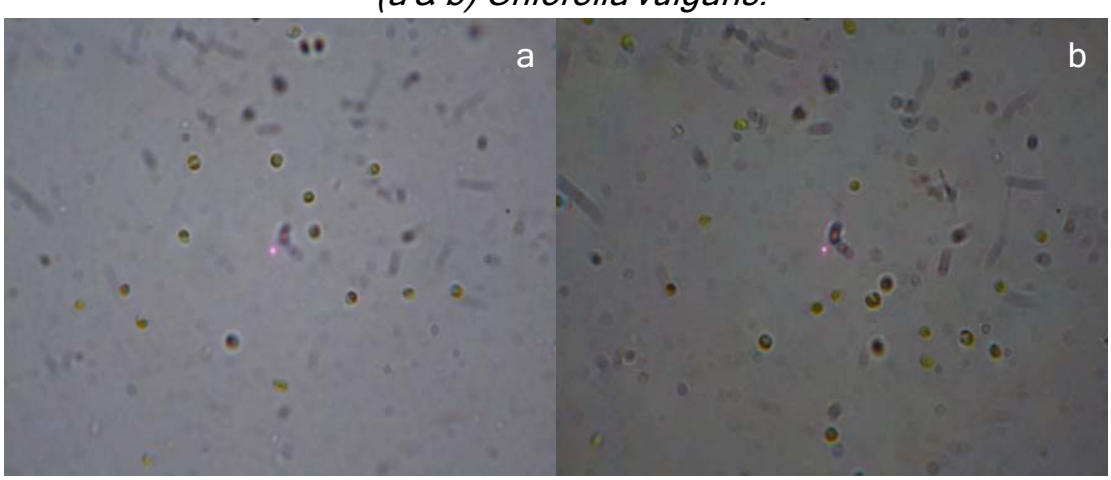

Microscopic observations: Algae from Kabaleeshwarar temple tank (South India) shows vegetative cells are in unicellular, spherical about 5-10 $\mu \mathrm{m}$ in size and surrounded by a cell wall which consists of two regions (Fig.1a \& b), an outer thin layer and an inner bulky microfibrillar layer. No trilaminar outer component of sporopollenin was observed at any stage of the cell cycle. The cells were identified as Chlorella vulgaris (Yamada \& Sakaguchi, 1982).

Nile red staining observations: Intracellular lipid droplets

\section{Gas chromatography \& mass spectroscopic} studies

The collected biodiesel was processed by GC and MS (JEOL GC mate) equipped with secondary electron multiplier. Lipid fraction was suspended in $\mathrm{n}$-hexane and applied to silica gel column chromatography. Aliphatic hydrocarbon fraction passes through the column fatty acid and carotenoid fractions were trapped. Passing through fraction was defined as hydrocarbon fraction, lipid components in hydrocarbon fraction were identified by GC/MS. The sample $(1 \mu \mathrm{l})$ was evaporated in a split less injector at $300^{\circ} \mathrm{C}$.

Fig. 2. Fluroscence Microscopic images of Chlorella vulgaris stained by Nile Red. The lipid drops are yellow in colour(a and b).
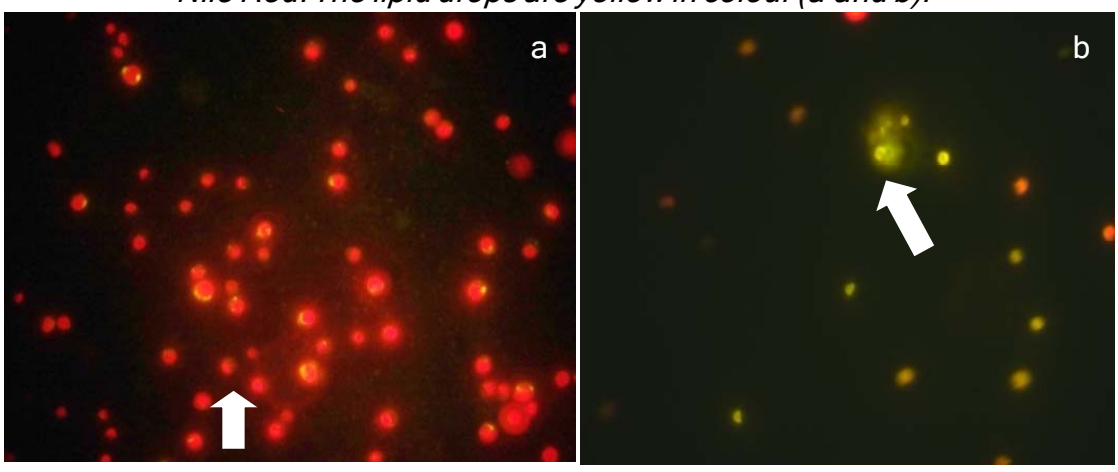

"Algal biodiesel" http://www.indjst.org
Elumalai et al. Indian J.Sci.Technol. 
of microalgae observed by Nile red staining under fluorescence microscopy, neutral lipids including hydrocarbons and triglycerides were stained in yellow, while polar lipids were stained in red (Fig. 2a \& b).

Table 1. Composition (\%) of group of fatty acids from

Chlorella vulgaris under day and night conditions.

\begin{tabular}{|c|c|c|c|}
\hline Fatty acids & Double bonds & $\begin{array}{c}\text { Under } \\
\text { light (\%) }\end{array}$ & $\begin{array}{c}\text { Under } \\
\text { dark (\%) }\end{array}$ \\
\hline Saturates & 0 & 38 & 55 \\
Monoenes & 1 & 21 & 15 \\
Polyenes & $\geq 2$ & 40 & 29 \\
\hline
\end{tabular}

Table 2. Molecular weight and retention time of saturated fatty acid obtain from GC-MS.

\begin{tabular}{|l|c|c|c|}
\hline \multirow{4}{*}{ Fatty acids } & \multicolumn{2}{|c|}{ Retention time } & $\begin{array}{c}\text { Molecular } \\
\text { weight }(\mathrm{g} / \mathrm{mol})\end{array}$ \\
\cline { 2 - 3 } & Night & Day & \multicolumn{2}{|c|}{} \\
\hline Saturated fatty acids & 3.23 & 3.03 & 74.08 \\
\hline Propionic acid & - & 4.7 & 88.11 \\
\hline Butyric acid & 8.05 & 7.27 & 144.21 \\
\hline Caprylic acid & 10.33 & 9.5 & 176.26 \\
\hline Capric acid & 12.36 & 12.68 & 200.31 \\
\hline Lauric acid & 14.15 & 13.06 & 228.37 \\
\hline Myristic acid & 15.74 & 15.94 & 264 \\
\hline Poly unsaturated fatty acids & 17.21 & 17.6 & 290 \\
\hline Hexadecatrienoic acid & 19.77 & 19.16 & 316 \\
\hline Stearidonic acid & 21.99 & 22.61 & 342 \\
\hline Eicosapentaenoic acid & 19.6 \\
\hline Docosahexaenoic acid & 21.9
\end{tabular}

Gas chromatography \& mass spectroscopy: By growing microalgae such as Chlorella vulgaris under light and dark condition in separately yields $0.2 \mathrm{~g} / \mathrm{l}$ cells which can be collected as a paste through sterile fine cloth then eventually dried. After extraction the oil content of growing under light shows yellowish liquid but the algae from dark condition give brownish colour. In this study, petroleum ether solvent system was used for esterification of high lipids from microalgae biomass. Three types of fatty acids such as saturates, monoenes, polyenes found in extracts (Table 1). Saturated fatty acids are $38 \%$ and $55 \%$, monounsaturated fatty acids $21 \%$ and $15 \%$ and poly unsaturated fatty acids $40 \%$ and $29 \%$ respectively. The high content of saturated fatty acids presenting microalgae under the dark condition. But the PUFAs are highly present in algae from light condition. The biosynthesis of these molecules does not occur mainly during the exponential phase

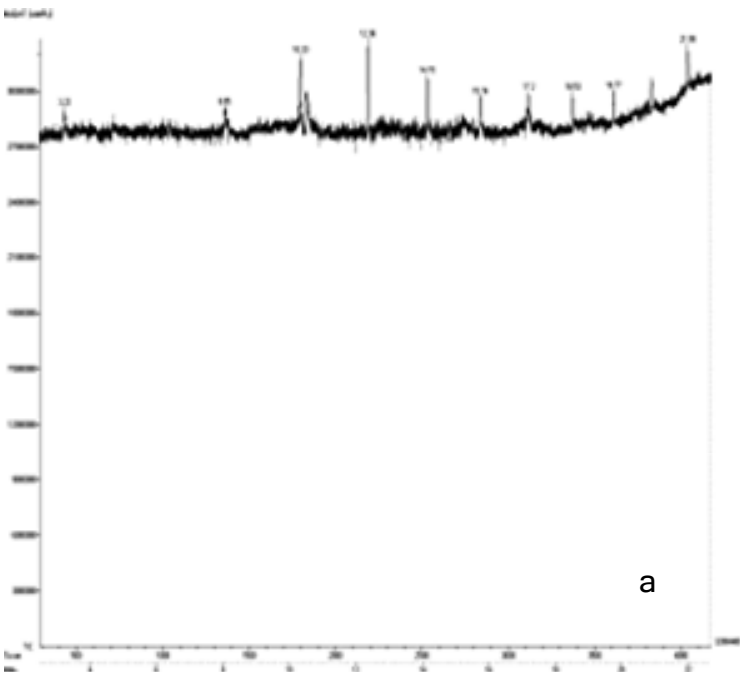

Fig. 3. GC of nightsample (a) and day sample (b). contain saturated fatty acids and PUFAs in vaious ratios (Table 3). The algae from dark sample shows rich in saturated fatty acid (capric acid, lauric acid \& myristic acid) and considerable amount of PUFA
(hexadecatrienoic acid, stearidonic acid, acid) and considerable amount of PUFA
(hexadecatrienoic acid, stearidonic acid, eicosapenaenoic acid, docosahexaenoic acid) when compare to algae grown under light. So the algae grown
in dark condition is an excellent source for high yield of compare to algae grown under light. So the algae grown
in dark condition is an excellent source for high yield of saturated fatty acids.

FT-IR spectroscopy: Five maxima of the generation of volatile products can be found in the spectrum. All collected extractions give bands at 706 and $3339 \mathrm{~cm}^{-1}$ (Fig. 6) so all are cis isomer, as expected from alga lipid because trans isomers produce a strong band at $970 \mathrm{~cm}^{-1}$ and a weak band at $3012 \mathrm{~cm}^{-1}$ while cis isomers gave medium nearby 720 and $3012 \mathrm{~cm}^{-1}$ bands. An analysis of the IR spectrum showed (Fig. 6 \& 7) the main composition stage, reveals the existence of the

absorption bands characteristic of these five different

of growth where the carbon source gives rise to lipids that also ATP to build up all the molecules necessary for the construction of the cell. As in the case for the biosynthesis of secondary metabolites, the fatty acids
appear after the end of the exponential phase of growth. The retention time and molecular weight of condition algae are compared (Table 2). By GC-MS, we were able to get different fractions such as saturated fatty acid, MUFAs and PUFAs, in these the Saturated fatty
acid and PUFAs are particularly interesting and it was compared in both light and dark grown algae. The GC peak variations of fatty acids. High peak areas were compared to day time sample (Fig. $3 b$ \& 5). The percentage of different fatty acids present in microalgae was analyzed with light and dark grown samples which obtained in dark condition sample (Fig. 3a \& 4) while 
Fig. 4. MS spectrum of Capricacid (a), Lauric acid (b), Myristic acid (c), Hexadecatrienoic acid (d), Stearidonicacid (e), Eicosapentaenoic acid (f), Docosahexaenoic acid $(g)$ from dark condition sample.
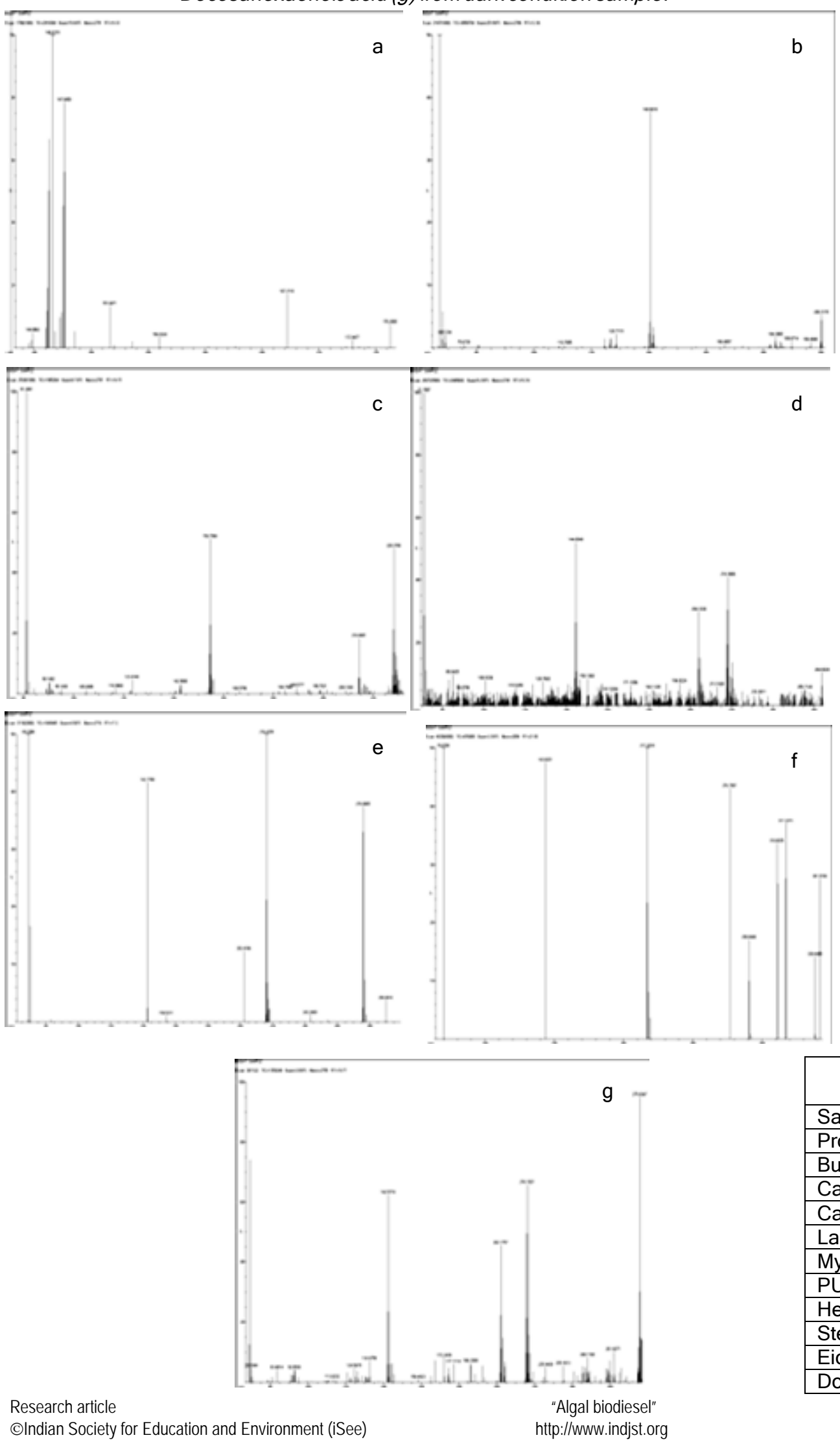
saturates, and UFAs from oils of day \& night samples.

bonds:

- $\mathrm{C}=\mathrm{O}$ : The main characteristic of the IR spectra of carbonylic compounds (aldehydes, acids, etc.) is the strong $\mathrm{C}=\mathrm{O}$ stretching absorption band in the region of $1870-1540 \mathrm{~cm}^{-1}$. In the case of esters, this band appears in the $1750-1735 \mathrm{~cm}^{-1}$.

- $\mathrm{C}-\mathrm{O}-\mathrm{C}$ : corresponding to ethers. These stretching vibrations produce a strong band in the $1200-900 \mathrm{~cm}^{-1}$ region.

- $\mathrm{C}-\mathrm{H}$ : absorption bands characteristic of the vibrations of $\mathrm{C}-\mathrm{H}$ bonds, as an example, 2960 and $2875 \mathrm{~cm}^{-1}$ correspond to the asymmetric and symmetric vibrational modes of methyl groups, respectively, and 2929 and $2850 \mathrm{~cm}^{-1}$ correspond to the asymmetric and symmetric vibrational modes of methylene groups, respectively.

- $\mathrm{CO}_{2}$ : they produce strong bands in between $2800-2000 \mathrm{~cm}^{-1}$ as well as in $700 \mathrm{~cm}^{-1}$ region.

- $\mathrm{H}_{2} \mathrm{O}$ : the adsorption bands of water can be observed in the range of $1800-1200 \mathrm{~cm}^{-1}$.

As many algal species have been found to grow rapidly and produce substantial amounts of TAG or oil and are thus referred to as oleaginous algae. It has long been postulated that algae could be employed as a cell factories to produce oils and other lipids for biofuel and other

\begin{tabular}{|l|c|c|}
\hline \multirow{2}{*}{ Fatty acids } & \multicolumn{2}{c|}{ Percentage (\%) } \\
\cline { 2 - 3 } & Day & Night \\
\hline Saturated fatty acids \\
\hline Propionic acid & 17.03 & 13.07 \\
\hline Butyric acid & 28.88 & - \\
\hline Caprylic acid & 10.37 & 05.53 \\
\hline Capric acid & 27.99 & 16.82 \\
\hline Lauric acid & 14.87 & 43.16 \\
\hline Myristic acid & 0.82 & 21.83 \\
\hline PUFAs & 18.57 & 17.02 \\
\hline Hexadecatrienoic acid & 18.02 & 21.73 \\
\hline Stearidonic acid & 17.89 & 25.54 \\
\hline Eicosapentaenoic acid & 45.49 & 35.80 \\
\hline Docosahexaenoic acid & Elumalai et al. \\
\hline \multicolumn{3}{|c|}{ Indian J.Sci.Technol. }
\end{tabular}


Fig. 5. MS spectrum of Capric acid (a), Lauric acid (b), Myristic acid (c), Hexadecatrienoicacid (d), Stearidonicacid(e),

Eicosapentaenoicacid (f) from daycondition sample.
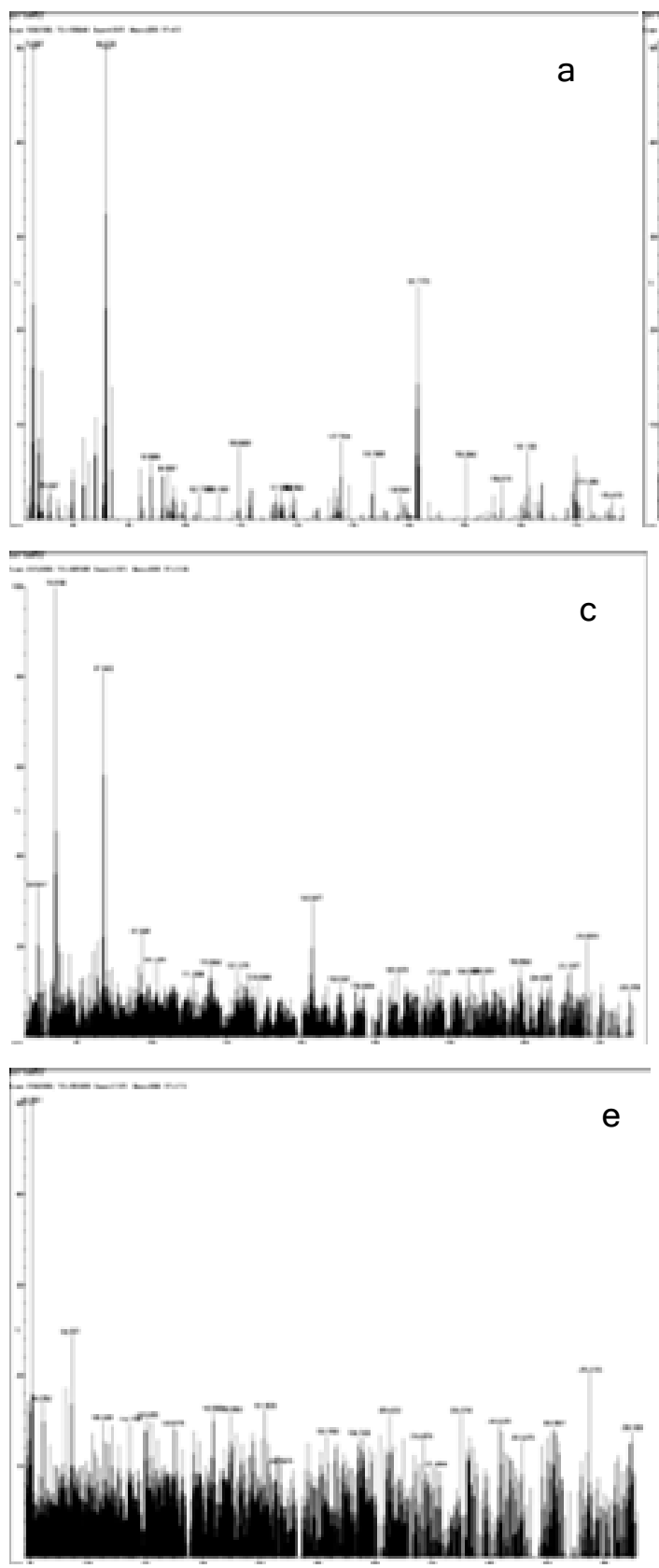

biomaterials (Benemann et al., 1982). The potential advantages of algae as feed stocks for biofuel and biomaterials include their ability to: 1) Synthesize and accumulate large quantities of neutral lipids/oil (20-50\% DCW), 2) Grow at high rates (e.g.1-3 doublings/d), 3) Thrive in saline / brackish water / coastal sea water for which there are few competing demands, 4) Tolerate marginal lands (e.g. desert, arid - and semi - arid lands) that are not suitable for conventional agriculture, 5) Utilize growth nutrients such as nitrogen and phosphorus from a variety of waste water source providing the additional
Vol. 4 No. 2 (Feb 2011)

ISSN: 0974- 6846

benefit of wastewater bio-remediation,

Reduce emissions of a major green house gas, 7) Produce value-added co-products or byproducts (e.g. bio polymers, proteins, polysaccharides, pigments, animal feed, fertilizer \& $\mathrm{H}_{2}$ ) and 8) Grow in suitable culture vessels (photobioreactors) throughout the year with annual biomass productivity, on an area basis, exceeding that of terrestrial plants by approximately ten fold.

There is an increase in total lipids stationary phase of algal cells or cells maintained under various stress conditions consisted primarily of neutral lipids, mainly TAGs. This was due to the shift in lipid metabolism from membrane lipid synthesis to the storage of neutral lipids. De novo biosynthesis and conversion of certain existing membrane polar lipids into triacylglycerols may contribute to the overall increase in TAG. As a result, TAGs may account for as much as $80 \%$ of the total lipid content in the cell 1974). (Klyachko-Gurvich,

Lipid accumulation by microalgae

Spoehr and Milner (1949) published detailed information on the effects of environmental conditions on algal composition and described the effect of varying nitrogen supply on the lipid and chlorophyll content of Chlorella and some diatoms. Investigations by Collyer and Fogg (1955) demonstrated that the fatty acid content of most green algae was between 10 and $30 \%$ DCW. In addition to nutrition, fatty acid and lipid composition and content were also found to be influenced by a number of 

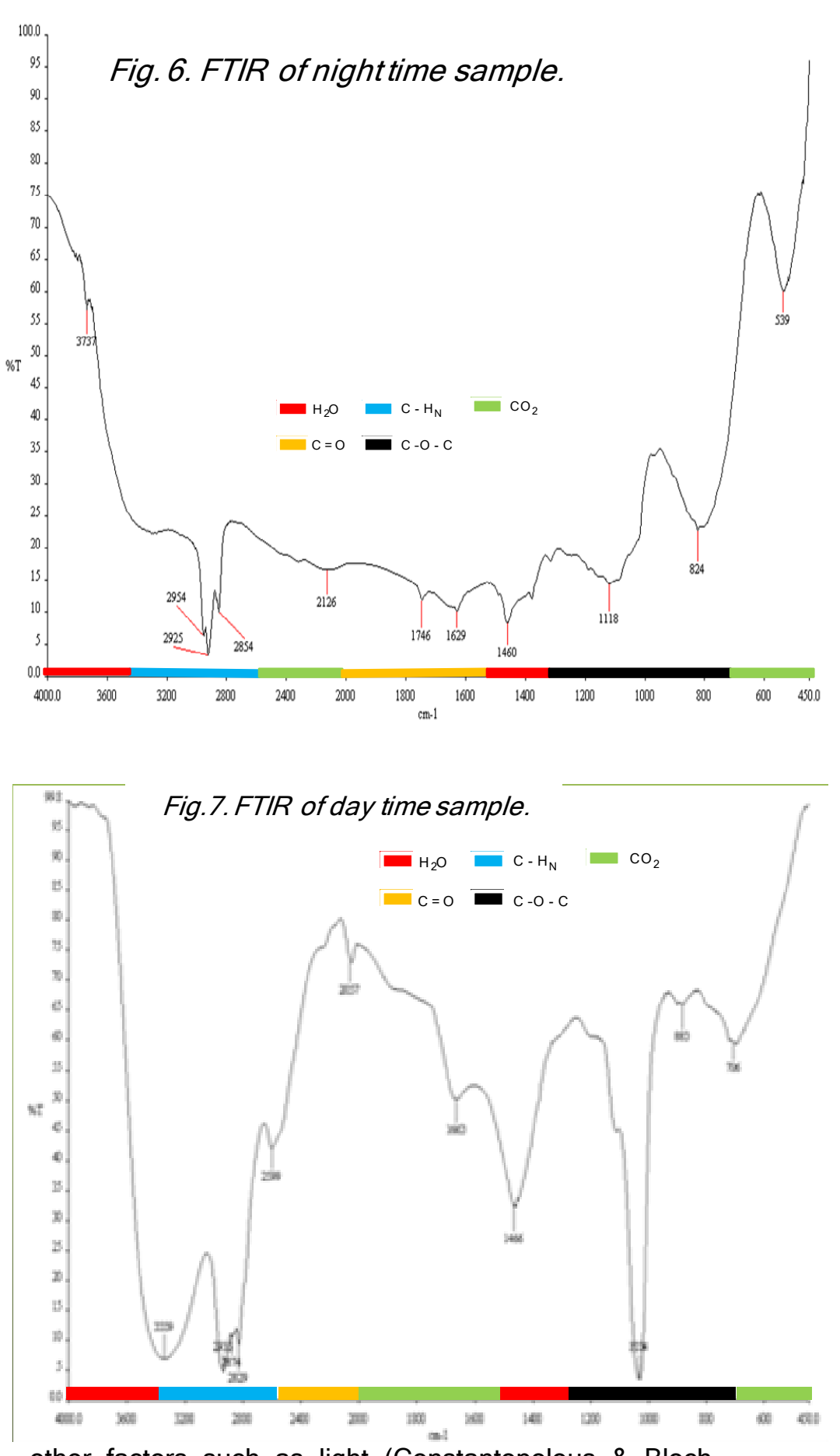

Vol. 4 No. 2 (Feb 2011)

ISSN: 0974- 6846

are low, and the dynamic range of the signal is quite compressed). However, new tagsequencing methodologies such as 454 and Solexa, which can give an accurate wholegenome picture of expression data, have the potential to provide a quantitative picture of them RNAs in algal samples.

\section{Conclusion}

The present work concluded that light stress conditions in the natural habitats of $C$. vulgaris did affect the lipids in this alga. Our results evidences that $C$. vulgaris is capable of regulating lipid metabolism depending on the light and dark conditions.

C. vulgaris is able to change the lipid content and the composition of FAs both in total lipid pool and individual lipids. In dark grown algae the concentration of saturated fatty acids increased while in C. vulgaris grown at light this lipid was enriched in unsaturated fatty acids. The difference in lipid composition of $C$. vulgaris grown under light and dark condition may be considered as one of the adaptive responses of the algal cells to the varying growth conditions. Therefore, the survival of algae under changed environmental conditions might be attributed to the functioning of the membranes. Since lipids are the structural components of the chloroplast membranes where photosynthetic apparatus is formed, and it is possible to assume that changes in the lipid content and their ratio are necessary for readjustment of the structure of chloroplast membranes of $C$. vulgaris to provide the efficient lipid synthesis under the dark conditions.

\section{Acknowledgement}

The authors are thankful to The Principal, Presidency College and Head, Department of Plant Biotechnology, Presidency College, Chennai for providing the laboratory and necessary facility. The Authors are very much thankful to Defence Research and Development Organisation (DRDO) Government of India for partial financial assistance to this project. The algal identification and photography was done in Plant Anatomy Research Centre (PARC), Tambaram, Chennai.

other factors such as light (Constantopolous \& Bloch, 1967) and low temperatures (Ackman et al., 1968). With the advent of the oil embargo in the early 1970s, a search for alternative energy sources set the stage for an almost 20 year research effort devoted to biofuel production from algal lipids. Future biofuel related studies may recognize limitations to the information that can be provided by high-density microarrays (the low signal-to-noise level limits identification of genes whose mRNA copy numbers

\section{References}

1. Ackman RG, Tocher CS and McLachlan J (1968) Marine phytoplankter fatty acid. J. Fisheries Res. Bd. Can. 25, 1603-1620.

2. Benemann JR, Goebel RP, Weissman JC and Augenstein DC (1982) Microalgae as a source of 
liquid fuels, final technical report to US dept. of energy. Washington DC, US dept. of energy. SAN003-4-2.

3. Collyer DM and Fogg GE (1955) Studies on fat accumulation by algae. J. Exp. Bot. 6, 256-75.

4. Constantopolous G and Bloch K (1967) Effect of light intensity on the lipid composition of Euglena gracilis. J. Biol. Chem. 242, 3538-3542.

5. Fulton $L$ (2004) Biomass and agriculture sustainability, markets and policies. International energy agency (IEA) biofuels study-interim report: Result and key messages so far. IEA, France, OECD Publication Service, pp105-112.

6. Greenspan P, Mayer EP and Fowler SD (1985) Nile red: A selective fluorescent stain for intracellular lipid droplets. J. Cell Biol. 100, 965-973.

7. Hu Q, Sommerfeld M, Jarvis E, Ghirardi M, Posewitz $M$, Seibert M and Darzins Al (2008) Microalgal triacylglycerols as feed stocks for biofuel production: Perspective and advances. Plant J. 54, 621-639.

8. Huang G, Chen F, Wei D, Zhang, $X$ and Chen G (2010) Biodiesel production by microalgal biotechnology. Appl. Energy. 87, 38-46.

9. Khan SA, Rashmi Mir. Z. Husain, Prasad $S$ and Banerjee UC (2009) Prospects of biodiesel production from microalgae in India. Renew. Sustain. Energy Rev. 13, 2361-2372.

10.Klyachko-Gurvich GL (1974) Changes in the content and composition of triacyl glyceride fattyacids during restoration of Chlorella pyrenoidosa cells after nitrogen starvation. Soviet Plant Physiol. 21, 611-618.

11. Matsunaga $T$, Matsumoto $M$, Maeda $Y$, Sugiyama $H$, Sato R and Tanaka T (2009) Characterization of marine microalga, Scenedesmus sp. strain JPCC GA0024 toward biofuel production. 31(9), 1367-1372.

12. Miao X and Wu Q (2006) Biodiesel production from heterotrophic microalgal oil. Biores. Technol. 97, 841846.

13. Milne TA, Evans RJ and Nagle N (1990) Catalytic conversion of microalgae and vegetable oils to premium gasoline with shape selective zeolites. Biomass. 21, 219-232.

14.Pratoomyot J, Srivilas $P$ and Noiraksar T (2005) Fatty acid composition of 10 microalgal species. J. Sci. Tech. 27(6), 1171-1189.

15. Rosen $\mathrm{BH}$ (1990) Identification manual For microalgae used in aquaculture. Florida Aqua Farms, Dade City, Florida. pp: 12-20.

16.Sharif Hossain ABM and Salleh A (2008) Biodiesel fuel production from algae as renewable energy. Amer. J. Biochem. Biotechnol. 4(3), 250-254.

17.Spoehr HA and Milner HW (1949) The chemical composition of Chlorella; effect of environmental conditions. Pl.Physiol. 24, 120-149.

18. Widjaja A (2009) Lipid production from microalgae as promising candidate for biodiesel production. Makara Teknologi. 13, (1), 47-51.
Vol. 4 No. 2 (Feb 2011)

ISSN: 0974- 6846

19.Yamada T and Sakaguchi K (1982) Electron microscopic studies of Chlorella ellipsoidea protoplast formation. J. Gen. Microbiol. 128(13), 19-1327. 